\title{
Ölçü Transformatörlerinin Elektrik Alan Analizleri
}

\author{
Y1ldırım Özüpak* \\ Dicle Üniversitesi, Silvan Meslek Yüksekokulu, Elektrik ve Enerji Bölümü, Diyarbakır, Türkiye, (ORCID: 0000-0001-8461-8702), yildirimozupak@gmail.com
}

(2nd International Conference on Access to Recent Advances in Engineering and Digitalization (ARACONF)-10-12 March 2021)

(DOI: 10.31590 /ejosat.916018)

ATIF/REFERENCE: Özüpak, Y. (2021). Ölçü Transformatörlerinin Elektrik Alan Analizleri. Avrupa Bilim ve Teknoloji Dergisi, (24), 497-501.

\section{$\ddot{O} z$}

Transformatörler sargılarında beklenmedik bir anda oluşan aşırı gerilim ve akımlara karşı transformatörün mekanik açıdan dayanıklılığının tahmin edilebilmesi, transformatör üreticileri için tasarım sürecinde çok önemlidir. Ani olarak meydana gelen yüksek gerilim ve akımlar elektrik güç sistemleri öenm teşkil etmektedir. Bu nedenle beklenmedik ani akım ve gerilimlerin analizlerinin doğru gerçekleştirilmesi güç sistemlerinde son derecede önemlidir. Ani olarak meydana gelen akımlara karşı transformatörlerin mekanik dayanımının sağlanabilmesi için tasarım sürecinde aşırı akımlara maruz kalan kısımların belirlenmesi gerekmektedir. Bu çalışmada, Maxwell ortamında modelllenen ölçü transformatörlerinin, elektrik alan dağılımları, transformatörlerin sargılarında meydana gelen aşırı akımlar, yalıtım malzemelerinde meydana gelen zorlanmalar ve sargılardaki elektrik alan-gerilim dağılımı ilişkileri analiz edilmiştir. Bunun için Sonlu Elemanlar Yöntemi'ne (SEY) dayanarak çözüm gerçekleştiren ANSYS@Maxwell yazılım programı ile transformatörlerin 2D modelleri kullanılmıştır. Bu sayede, sargılardaki elektrik alan-gerilimi dağılımları, mekanik dayanımın az olduğu bölgeler ve yalıtım malzemelerinde bozulmaya neden olabilecek kritik bölgeler belirlenmiştir.

Anahtar Kelimeler: Elektrik alanı, Ölçü transformatörü, SEY, Maxwell-3D.

\section{Electric Field Analysis of Instrument Transformers}

\begin{abstract}
Predicting the mechanical strength of the transformer against overvoltages and currents unexpectedly occurring in transformer windings is very important for transformer manufacturers in the design process. Suddenly occurring high voltages and currents are important in electrical power systems. Therefore, accurate analysis of unexpected inrush current and voltage is extremely important in power systems. In order to ensure the mechanical strength of transformers against suddenly occurring currents, the parts exposed to excessive currents must be determined during the design process. In this study, the electric field distributions of the instrument transformers modeled in the Maxwell environment, the overcurrents in the transformers' windings, the stresses in the insulation materials and the electric field-voltage distribution relations in the windings are analyzed. For this, 2D models of transformers were used with ANSYS@Maxwell software program, which realizes a solution based on Finite Element Method (FEM). Thus, electric field-voltage distributions in the windings, regions with low mechanical strength and critical regions that may cause deterioration in insulation materials were determined.
\end{abstract}

Keywords: Electric field, ransformer, FEM, Maxwell-3D.

\footnotetext{
*Sorumlu Yazar: yildirimozupak@gmail.com
} 


\section{Giriş}

Transformatörler, elektrik enerjisini farklı voltaj seviyelerinde kullanmak için çok önemli elektrik makineleridir. Yıldırım darbesi, aşırı gerilim nedeniyle tüm elektrik güç sistemleri için çok önemli bir olgudur. Bu nedenle yıldırım darbe analizi, güç sistemlerini yıldırım hasarlarına karşı korumak için önemli bir çalışmadır. Literatürde simülasyon programları kullanılarak transformatörlerin yıldırım analizi ve yalıtım malzemeleri ile ilgili bazı çalışmalar bulunmaktadır.

Darbe geriliminin sargılar içerisindeki dağılımı ve darbeye maruz kalmayan sargilardaki etkinin incelenmesi amacıyla yıldırım darbe geriliminin net bir şekilde analiz edilmesi önemli bir hal almıştır. Özellikle darbeye maruz kalmayan sargıların izolasyon yapısı belirlenmelidir. Ayrica sarımda kullanılan aparatların izolasyon malzemeleriyle olan koordinasyonunun sağlanması gereklidir.

Trafo sargıları üzerindeki yıldırım-darbe gerilim dağılımlarının analizlerini, azaltılmış ölçekli modele dayalı trafo sargılarındaki geçici aşırı gerilim dağılımının analizini, sonlu eleman modellerini ve geçici potansiyel ve alan dağılımının hesaplanması için yıldırım darbe testini içerir (Özüpak ve Mamiş, 2019; Heatcote, 2007; Turan ve Çekirdekli, 2007). Güç transformatörlerinin sarg1 sisteminde, geçici rejim altında güç transformatöründe modelleme ve yalıtım tasarım metodolojisi, yıldırım darbesi modellemesi ve güç ve dağıtım transformatörlerinin simülasyonu gerçekleştirilmiştir ( Wojda ve ark., 2013; Özüpak ve ark., 2019). Devre tekniğine bağlı SEY yıldırım darbesi altında bir güç trafosunun sargı ve yalıtım tasarımlarının geçici analizi için, yıldırım darbe analizi ile kuru tip bir transformatörün ayrıntılı bir modeli için birleştirilmiş analitik ve SEY yöntemleri incelenmiştir (Yazdani ve ark., 2013). Yıldırım darbe analizi transformatör yağında yük taşımasında iyonik ayrışma, güç aktarımında iç yalıtım tasarımı iyileştirmeleri için elektrik alan analizine sahip transformatörler, dağıtım güç transformatörleri aracılığıyla yıldırımın neden olduğu aşırı gerilimlerin hesaplanması gerçekleştirilmiştir.

$\mathrm{Bu}$ makalenin katkıları şunları içerir: Yıldırım darbesinin elektrik alan dağılımı üzerindeki etkisi ayrıntılı olarak tartışılmıştır. Sargının elektrik alan dağılımları araştırılmış ve 2-B sonlu elemanlar yöntemi (SEY) kullanılarak analiz edilmiştir. Yıldırım darbesinin elektrik alan dağılımına etkisi, daha önceki çalışmalarda araştırılmamış olan konularda ayrıntılı olarak tartışılmıştır. Aralıklı sargı yapısı, transformatörlerin kaçak endüktansını azaltabildiği görülmüştür. Elektrik alan dağılımı ve analiz sonuçlarının incelenmesi için önerilen yöntemin, transformatörlerde elektrik alan dağılımının iyileştirilmesine katkı sağlaması beklenmektedir.

\section{Materyal ve Metot}

\subsection{Tasarımla İlgili Hususlar}

Bir tasarımda, bir makinenin gerçekleştirilmesi için bilim, teknoloji ve icatların uygulanması ile gerekli performans ve özellikleri karşılayacak bir kavram biçimlendirilir. Bir tasarım süreci yalnızca mühendislik hesaplamaları değildir, aynı zamanda tasarım temeli, spesifikasyonlar, tasarım aktarımı ve bilgi güncellemesinin dikkatli bir şekilde değerlendirilmesini içerir.

Bir transformatörün karşılaması gereken özellikleri ve spesifikasyonları bilerek, ana tasarım alanları şunları içerir:

e-ISSN: 2148-2683
Manyetik devre; çekirdek, pencere vb.

$\square$ Elektrik devresi; sargilar.

Yalitım

$\square$ Mekanik yap1

Tasarımcının işi, alanı çerçeveye, çekirdeğe, hava boşluğuna, sargılara, yalıtıma ve transformatördeki soğutma devresine uygun şekilde tahsis etmektir. Dahası, üretim maliyetlerinde ekonomi, işletme ve işletme maliyetleri de göz önünde tutulur.

Tasarımda aşağıdaki nedenlerden dolayı sınırlamalar getirilmiştir:
$\square$ Manyetik parçaların doygunluğu
$\square$ Yüksek çıktı altında sıcaklık artışı
$\checkmark$ Yüksek voltaj gradyanları nedeniyle yalıtım arızası.

\section{2. Ölçü Transformatörlerinin Modellenmesi}

Transformatör modelinde, sınır koşulları, dış geometri ve tüm materyallerin özellikleri üzerinde tanımlanmaktadır. Ölçü trafolarının Maxwell ortamında tasarlanan prototipleri Şekil 1 ve Şekil 2‘de verilmiştir.

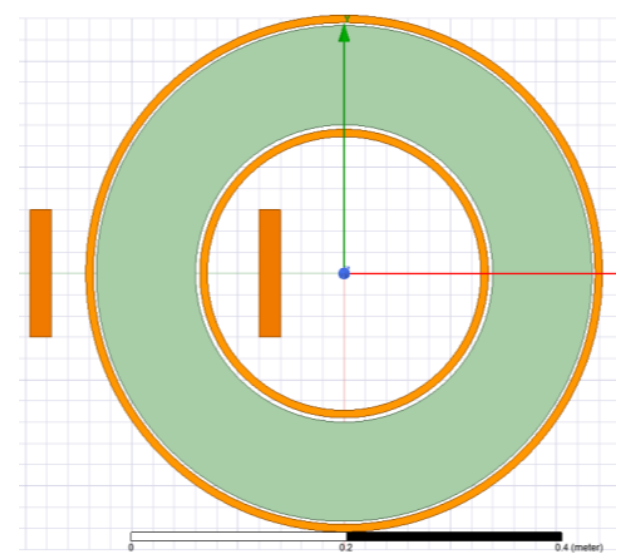

Şekil 1. Ak1 transformatörü.

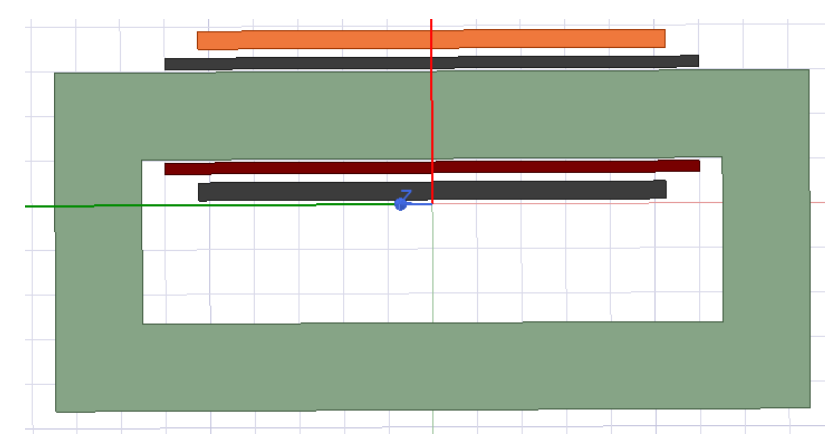

Şekil 2. Gerilim transformatörü.

Manyetik çekirdek, manyetizasyonun Şekil 3'de verilen B-H eğrisi gibi ince laminasyonlarla karakterize edilir. Şekil 4 B-P eğrisini temsil etmektedir. 


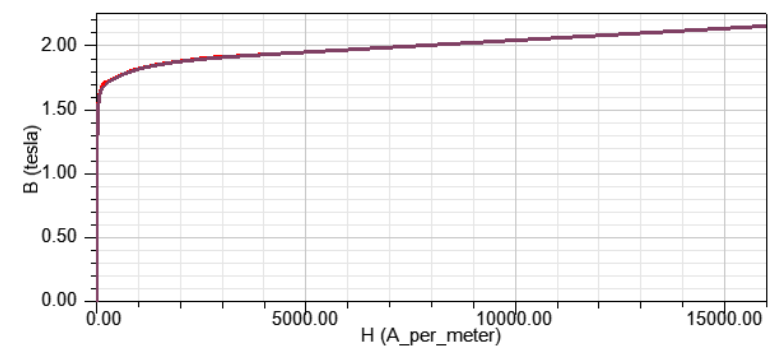

Şekil 3. Çekirdek laminasyonlarının B-H eğrisi

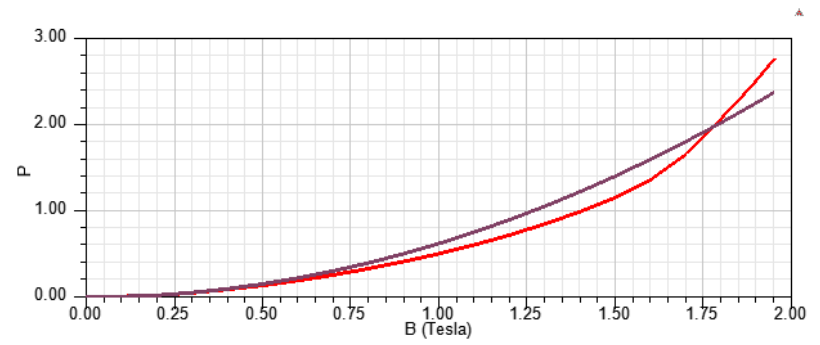

Şekil 4. Çekirdek yoğunluğunun P-B eğrisi

Transformatörün işletmede kullanımı sırasında yüksek frekanslı aşırı gerilimlerden zarar görmeden çalışması için üretilen transformatörler standart olarak $1,2 \mu$ s tepe ve $50 \mu \mathrm{s}$ yarılanma süresi olan yıldırım darbe gerilimi ile test edilmiştir. Amaç en az üretim ve işletme maliyeti ile aşırı gerilimlere karşı dayanıklı y1llarca çalışan transformatör tasarlamaktır.

Normal çalışma koşullarındaki bir gerilim transformatörünün yıldırım darbesine karşı tepkisini analiz etmek için bu test gerçekleştirilmiştir. Burada amaç, ani gerilim dalgalanmalarında trafodaki elektrik alan dağılımını ve yalıtım malzemsindeki kuvvet etkilerini belirlemektir. Buna bağlı olarak trafoda meydana gelebilecek hasarı tasarım aşamasından önce belirlemektir. Ani akımı uygulamak için tasarlanan modelin AG sargılarına gerilim uyarması verilerek simülasyon gerçekleştirilmiştir. Yüksek gerilimi uygulamak için "SheetScan" yöntemi kullanılmış̧ır. Yeni bir koordinat sistemi ve eğri oluşturulmuştur. Analiz, 0-100 $\mu$ saniye aralı̆̆ında birer mikro-saniyelik aralıklarla gerçekleştirilmiştir. Uygulanan Ani yüksek gerilimin maksimum değeri 1 MV'dir.

\section{Araştırma Sonuçları ve Tartışma}

\subsection{Akım Transformatörünün Analizi}

Tasarlanan trafo ANSYS@Maxwell-3D ile simüle edilmiştir. Simülasyondan elde edilen elektrik alan dağılımları Şekil 5-10'da verilmiştir.

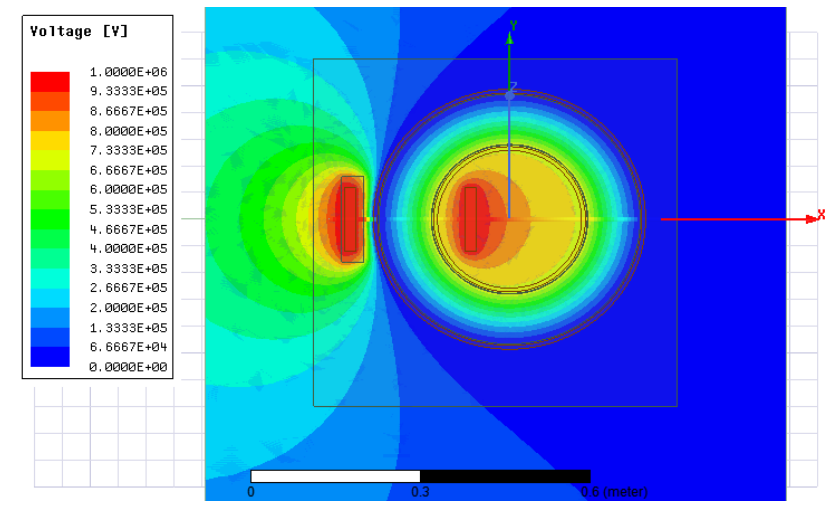

Şekil 5. Uygulanan gerilimin dağılımı
Gerilim seviyesi 1 MV ve analiz süresi için $0-50 \mu$ saniye aralığı için $1 \mu$ saniyelik adımlar seçilmiştir. Test gerçekleştirildikten sonra trafoda meydana gelen elektrik alan ve gerilim-elektrik alan dağılımı Şekil 6'da ve Şekil 7'de sunulmuştur.

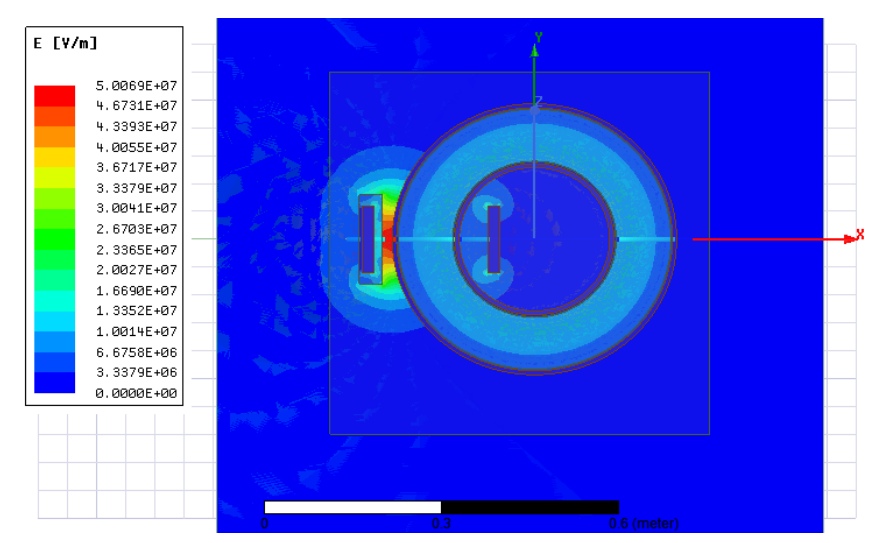

Şekil 6. 2D transformatör modelinin elektrik alanı

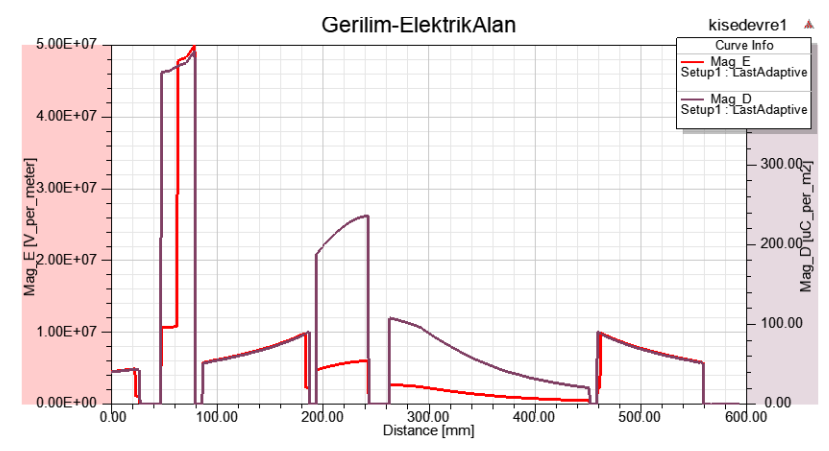

Şekil 7. Gerilim-elektrik alan dağılımı

Akım transformatörünün elektrik alan analizleri ANSYS@MAXWELL ortamında 2D olarak gerçekleştirilmiştir. Termal alan analizleri için çoklu fizik analizlerini birlikte gerçekleştirebilen ANSYS@MAXWELL ve ANSYS@Mecanical birleştirilerek analiz gerçekleştirilmiştir. Tasarlanan modelin geçici rejim çalışma koşullarındaki elektrik alan ve transformatörde meydana gelen kuvvet incelemeleri gerçekleştirilmiş̧ir. Normal çalışma koşullarında akım transformatörünün primer ve sekonder sargıları nominal akımları taşımaktadırlar.

\subsection{Gerilim Transformatörünün Analizi}

Normal çalışma koşullarındaki bir gerilim transformatörünün ani gerilimlere ve akımlara karşı tepkisini analiz etmek için bu test gerçekleştirilmiştir. Burada amaç, ani gerilim yükselmelerinde trafodaki elektrik alan dağılımını ve sargılardaki kuvvet etkilerini belirlemektir. Buna bağlı olarak trafoda meydana gelebilecek

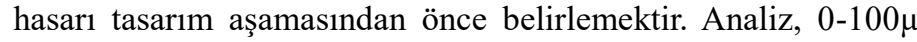
saniye aralığında birer mikro-saniyelik aralıklarla gerçekleştirilmiştir. Uygulanan gerilimin maksimum değeri 1 MV'dir. Şekil 8'de, uygulanan gerilimin trafodaki dağılımı ve değeri sunulmuştur. 


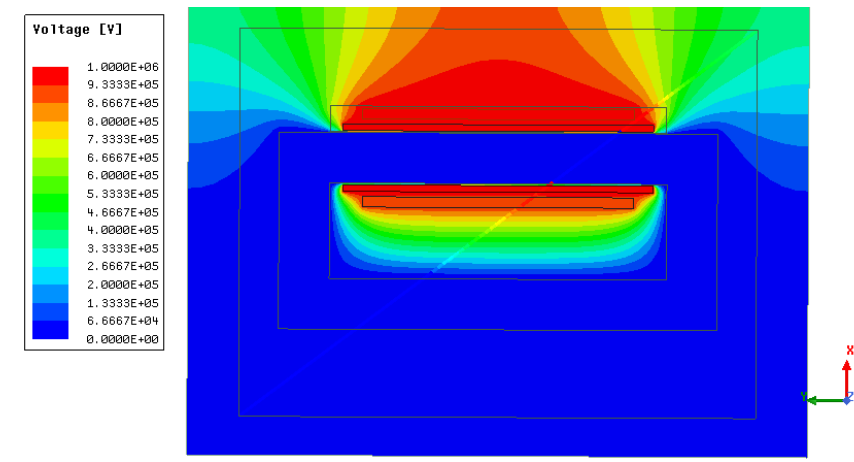

Şekil 8. Uygulanan gerilimin dağılımı.

Gerilim seviyesi 1 MV ve analiz süresi için $0-100 \mu$ saniye aralığ 1 için $1 \mu$ saniyelik adımlar seçilmiştir. Test gerçekleştirildikten sonra trafoda meydana gelen elektrik alan dağılımı ve elektrik alanının gerilim değerine bağlı olarak değişimi Şekil 9'da ve Şekil 10'da sunulmuştur.

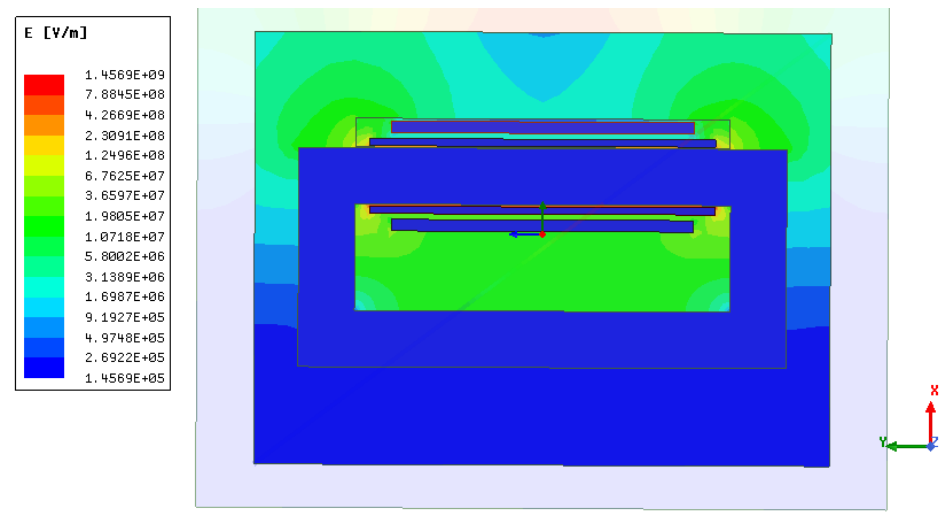

Şekil 9. 2D transformatör modelinin yüksek gerilimdeki elektrik alan dağılımı

\section{Sonuç}

Geçici rejim çalışma koşulunda nüvedeki manyetik akı yoğunluğu normal çalışma koşullarındak akı yoğunluğundan çok daha büyük olmuştur ve nüve doyuma gitmiş̧ir. Geçici rejim durumundaki akım normal çalışma şartlarındaki akımdan çok yüksek olmuştur. Oluşan bu yüksek akımda büyük elektromanyetik kuvvetler meydana getirmiş̧ir. Meydana gelen bu büyük elektromanyetik kuvvetler daha büyük elektrodinamik gerilimler meydana getirebilirler ve ölçü trafolarına ciddi zararlar

\section{Kaynakça}

Özüpak Y, MAMIS M. S. (2019) Realization of electromagnetic flux and thermal analyses of transformers by finite element method. IEEJ Transactions on Electrical and Electronic Engineering, 14(10), 1478-1484. Doi: 10.1002/tee.22966.

Heatcote M, (2007) J\&P Transformer Book. Thirteenth Edition, Oxford, United Kingdom, Newness An imprint on Elsevier.

Turan H, Çekirdekli D (2007) Hava Aralığ 1 Bulunan Reaktör Çeşitlerinin İrdelenmesi ve Bir Prototip için Uygulama

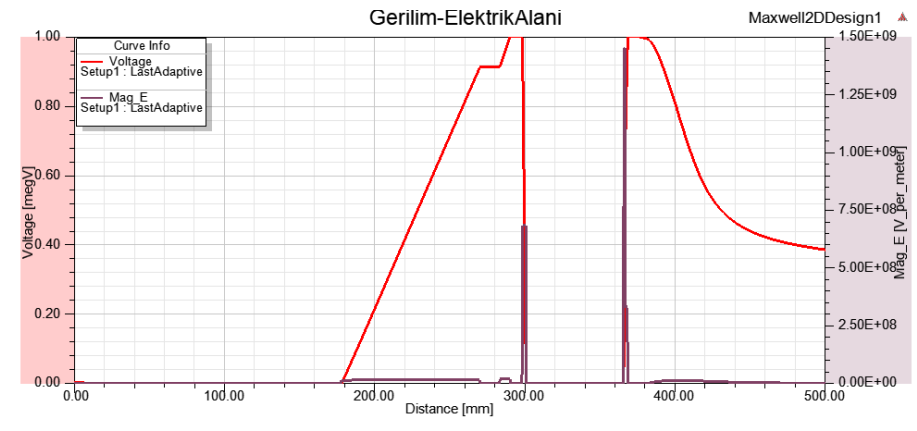

Şekil 10. Gerilim trafosunun gerilim-elektrik alan ilişkisi

Sonlu Elemanlar Yöntemine (SEY) dayanarak çözüm gerçekletiren ANSYS@Maxwell-2D ile gerilim trafosunun elektrik alan, elektromanyetik alan, termal alan, elektromanyetik kuvvet ve yıldırım darbe analizleri gerçekleştirilmiştir. Termal alan analizleri için çoklu fizik analizlerini birlikte gerçekleştirebilen ANSYS@Maxwell ve ANSYS@Mecanical birleştirilerek kullanılmıştır.

Kısa devre durumunda, büyük elektromanyetik kuvvetler meydana gelmektedir. Bu büyük elektromanyetik kuvvetler daha büyük elektrodinamik gerilimler meydana getirebilirler ve ölçü trafolarına ciddi zararlar verebilirler. Birleştirilmiş manyetik ve mekanik alan kullanılarak, mekanik dayanaklılık bakımdan gerilim trafosunun zayıf ve güçlü noktaları belirlenmiştir.

Gerilim trafosu geçici rejim olayındaki elektrik alan ve sargılardaki kuvvet değerleri aşağıda verilmiştir.

Elektrik alan $1.45 \times 10^{5} \mathrm{~V} / \mathrm{m}$

Maksimum elektromanyetik kuvvet $3411 \mathrm{~N}$

verebilirler. Birleştirilmiş manyetik ve mekanik alan kullanılarak, mekanik dayanaklılık bakımdan gerilim ve akım trafosunun zayıf ve güçlü noktaları belirlenmiştir. Her iki trafo için de elektrik alan dağılımı ve elektrik alanının gerilim değerine bağlı olarak değişimi elde edilmiş̧ir.

\section{Teşekkür}

Bu çalışma İnönü Üniversitesi Bilimsel Araştırma Projeleri Koordinasyon Birimince Desteklenmiştir. Proje Numarası: FBA2017-639. Katkılarından dolayı teşekkürler.

Örneği. Yüksek Lisans Tezi, Kocaeli Üniversitesi, Kocaeli, Türkiye.

Dönük A (2012) Modeling and Design of Iron-Core Shunt Reactors With Discretely Distributed Air-Gaps. Doktora Tezi, ODTÜ, Ankara, Turkey.

Zheng T, Zhao YJ, Ying J, Chen PL, Zhang FF (2015) “Design and analysis on the turn-to-turn fault protection scheme for the control winding of a magnetically controlled shunt reactor”. IEEE Transactions, 30(2), 967-975. 
Wojda R.P, Kazimierczuk, M.K (2013)"Analytical winding size optimisation for different conductor shapes using Ampère's Law", Power Electronics, IET, 6 (6), 1058-1068.

Özüpak Y, MAMIS M. S (2019) Realization of electromagnetic flux and thermal analyses of transformers by finite element method. IEEJ Transactions on Electrical and Electronic Engineering, 14(10), 1478-1484. Doi: 10.1002/tee.22966.

Özüpak Y, MAMIS M. S, TEKE İ. H (2019) Electromagnetic Field and Total Loss Analysis of Transformers by Finite Element Method. International Journal of Engineering And Computer Science, 8(1), 24451-24460. (Yayın No: 5774086)
Yazdani-Asrami M, Mirzaie M, Akmal A. S (2013) No-load loss calculation of distribution transformers supplied by nonsinusoidal voltage using three-dimensional finite element analysis, Energy, vol. 50, no. 1, pp. 205-219.

M. Ostrenko and B. Andriienko. (2017). "Transformer impulse surges calculation by FEM coupled to circuit," in IEEE Transactions on Magnetics, vol. 53, no. 6, pp. 1-4, June, Art no. 7401804 .

T. Zupan, B. Trkulja, R. Obrist, T. Franz, B. Cranganu-Cretu, and J. Smajic. (2016). Transformer windings rlc parameters calculation and lightning impulse voltage distribution simulation. IEEE Transactions on Magnetics, 52(3):1-4, March. 